\title{
arte 16
}

SÜLEYMAN DEMIREL ÜNIVERSITESI

GÜZEL SANATLAR FAKÜLTESI SANAT DERGIS

SDÜ ART-E Güzel Sanatlar Fakültesi Sanat Dergisi 2015, Sayı: 16, Cilt: 8, Kasım Aralık
ART-E Art Journal of SDU Fine Arts Faculty 2015, Vol:8, No:16, November-December

HAKEMLI DERGi//REFEREED JOURNAL

Imtiyaz Sahibi //Owner of the Journal

Prof. Dr. Mustafa Zihni TUNCA

Editör //Editor

Doç. Yusuf KEŞ

Editör Yardımcısı //Assistant Editor

Yrd. Doç. Ece ÇALIŞ ZEĞEREK

Kapak Tasarımı //Book Cover

Arş. Gör. Murat KARA

Dizgi //Composition

Arş. Gör. Münire YILDIZ

Arş. Gör. Sevtap SARICA

ART-E yılda iki kez yayınlanan, Hakemli, bilimsel bir e-dergidir. Dergide yayınlanan çalışmalardan, kaynak gösterilmek koşuluyla alıntı yapılabilir.

Çalışmaların tüm sorumluluğu yazarına-yazarlarına aittir.

SDÜ Arte - Güzel Sanatlar Fakültesi Sanat Dergisi,

EBSCO'nun Art Source veri tabanında tam metin olarak yer almaktadır.

SDÜ GSF Art-E Dergisi, Ankara Üniversitesi tarafından, öğretim üyeliği atama kriterleri çerçevesinde kabul edilen ulusal hakemli dergiler arasında yer almaktadır. 


\section{Yayın Kurulu//Board of Advisory}

Doç. Mehmet Özkartal

Doç. N. Rengin Oyman

Doç. Olcay Ataseven

Doç. Yusuf Keş

Yrd. Doç. Dr. Cenk Celasin

Yrd. Doç. Dr. Nil Ünlü Aycıl

Yrd. Doç. Dr. Özgün Can

Yrd. Doç. Serap Ünal

Prof. Dr. Ayten Er

Danışma Kurulu//Academic Referees

Prof. Dr. Atilla Atar

Prof. Dr. İrfan Erdoğan

Prof. Dr. Sezer Akarcalı

Prof. Dr. Barbaros Gürsel

Prof. Dr. Zeki Ceyhan

Prof. Dr. Gökay Yıldız

Prof. Dr. Namık Kemal Sarıkavak

Prof. Dr. Nuran Kayabaşı

Prof. Dr. Zeynep Erdoğan

Prof. Dr. Mustafa Arlı

Prof. Dr. M. Zeki Yıldırım

Prof. Dr. Ayten Sürür

Prof. Dr. İsmail Öztürk

Prof. Mehmet Saçlıoğlu

Prof. Şerife Atlıhan

Prof. Dr. Mevlüt Albayrak

Prof. Dr. Songül Sallan Gül

Prof. Dr. Hüseyin Gül

Prof. Dr. Murat Ali Dulupçu

Doç. Dr. Hamdi Bravo
Süleyman Demirel Üniversitesi

Süleyman Demirel Üniversitesi

Süleyman Demirel Üniversitesi

Süleyman Demirel Üniversitesi

Süleyman Demirel Üniversitesi

Süleyman Demirel Üniversitesi

Süleyman Demirel Üniversitesi

Süleyman Demirel Üniversitesi

Gazi Üniversitesi

Anadolu Üniversitesi

Gazi Üniversitesi

Ankara Üniversitesi

Marmara Üniversitesi

Anadolu Üniversitesi

Mehmet Akif Ersoy Üniversitesi

Hacettepe Üniversitesi

Ankara Üniversitesi

Ankara Üniversitesi

Ankara Üniversitesi

Mehmet Akif Ersoy Üniversitesi

Beykent Üniversitesi

Dokuz Eylül Üniversitesi

İstanbul Ticaret Üniversitesi

Marmara Üniversitesi

Süleyman Demirel Üniversitesi

Süleyman Demirel Üniversitesi

Süleyman Demirel Üniversitesi

Süleyman Demirel Üniversitesi

Ankara Üniversitesi 
Cilt 8, Sayı 15 ve Sayı 16

Hakem Kurulu//Arbitration Referees

Prof. Dr. Candan Terviel

Prof. Dr. Doğan Günay

Prof. Dr. Ece Korkut

Prof. Filiz Nurhan Ölmez

Prof. Dr. Halide Sarıoğlu

Prof. Dr. Hüseyin Elmas

Prof. Nuray Yılmaz

Prof. Namık Kemal Sarıkavak

Prof. Dr. Nuran Kayabaşı

Prof. Dr. Sema Etikan

Prof. Sıdıka Sibel Sevim

Prof. Dr. Sibel Karakelle

Prof. Soner Genç

Prof. Songül Karahasanoğlu

Prof. Şerife Atlıhan

Prof. Z. Rüçhan Şahinoğlu Altınel

Doç. Dr. Abdulgani Arıkan

Doç. Dr. Adnan Tönel

Doç. Dr. Ali Seylan

Doç. Dr. Ali Tomak

Doç. Düriye Kozlu

Doç. Dr. Emine Nas

Doç. Dr. Fatih Başbuğ

Doç.Dr. Gözde Çolakoğlu Sarı

Doç. Mehmet Özkartal

Doç. Olcay Ataseven

Doç. N. Rengin Oyman

Doç. Dr. Şevki Abdullah Duymaz

Doç. Dr. Uğur Atan

Doç. Yusuf Keş

Doç. Dr. Yüksel Göğebakan

Yrd. Doç. Dr. Aydın Zor

Yrd. Doç. Dr. Aysun Altınöz Yonuk

Yrd. Doç. Dr. Doğan Demirci

Yrd. Doç. Ece Çalış Zeğerek

Yrd. Doç. Dr. Feryal Söylemezoğlu

Yrd. Doç. Dr. Güler Bek Arat

Yrd. Doç. Mustafa Kınık

Yrd. Doç. Dr. Nurdan Kızıldeli Salık

Yrd. Doç. Yüksel Pirgon

Yrd. Doç. Serap Ünal

Yrd. Doç. Serenay Şahin

Yrd. Doç. Dr. Vedat Tezcan
Muğla Sıtkı Koçman Üniversitesi

Dokuz Eylül Üniversitesi

Hacettepe Üniversitesi

Ahi Evran Üniversitesi

Gazi Üniversitesi

Selçuk Üniversitesi

Dokuz Eylül Üniversitesi

Hacettepe Üniversitesi

Ankara Üniversitesi

Ahi Evran Üniversitesi

Anadolu Üniversitesi

Mehmet Akif Ersoy Üniversitesi

Anadolu Üniversitesi

İstanbul Teknik Üniversitesi

Marmara Üniversitesi

Marmara Üniversitesi

Selçuk Üniversitesi

Zirve Üniversitesi

Ondokuz Mayıs Üniversitesi

Ondokuz Mayıs Üniversitesi

Osman Gazi Üniversitesi

Selçuk Üniversitesi

Akdeniz Üniversitesi

İstanbul Teknik Üniversitesi

Süleyman Demirel Üniversitesi

Süleyman Demirel Üniversitesi

Süleyman Demirel Üniversitesi

Süleyman Demirel Üniversitesi

Selçuk Üniversitesi

Süleyman Demirel Üniversitesi

İnönü Üniversitesi

Akdeniz Üniversitesi

Gazi Üniversitesi

Süleyman Demirel Üniversitesi

Süleyman Demirel Üniversitesi

Ankara Üniversitesi

Süleyman Demirel Üniversitesi

Necmettin Erbakan Üniversitesi

Mehmet Akif Ersoy ÜNiversitesi

Süleyman Demirel Üniversitesi

Süleyman Demirel Üniversitesi

Osman Gazi Üniversitesi

Siirt Üniversitesi 


\section{IÇiNDEKILER//CONTENTS}

\section{Editörden//Editoryal}

- Yusuf KEŞ

\section{Makaleler//Articles}

- Banu Hatice Gürcüm, Ahmet Aytaç

Geleneksel ve Kültürel Unsurların Postmodernizm ile Birlikte Tekstil

Tasarımında Yükselişi

Appraising Traditional And Cultural Aspects In Textile Design With

Postmodernism

- Bilge Kınam Dokuzlar

Toplumsal Farkındalık için Grafik Tasarım

Graphic Design For Socially Awareness

\section{- Doğan Arslan}

Sanat ve Tasarımda Optik Illüzyona Bağlı Imge Kullanımı

Usage Of Optical Illusion Image In Art And Design

- H. Kübra Ergin

Performatif Eylemlerle Sanatsal Yıkım ve Şiddetin Araçları

Tools Of Artistic Destruction And Violence With Performative Actions

- Ibrahim Gökhan CEYLAN

Amblem ve Logo Tasarımlarında Renklerin Dili

The Language Of The Colours In Designin Of Emblem and Logo

\section{- Münire YILDIZ, Yusuf KEŞ}

Grafik Tasarımda Yeni Nesil Font Tasarımı

A New Generation Font Design In Graphic Design

\section{- Serkan Çalışkan, Z. Rüçhan Şahinoğlu Altınel}

Cumhuriyet Dönemi Türk Resiminde Mimaride Bayrak Imgesi

Image Of Flag Concerning Architecture In Republic Period Turkish Painting

- Sibel Sıdıka Sevim, Ezgi Hakan Verdu Martinez, Cemalettin Sevim

Brezilya'da Geleneksel Çömlekçilik Sanatı ve Florianopolis Örnekleri

Traditional Pottery In Brazil And Samples Of Florianopolis

\section{- Sultan SÖKMEN}

Bitlis Etnografya Müzesinde Bulunan Geleneksel Giysiler

Traditional Clothes Located At The Bitlis Ethnographical Museum 